\title{
REVOLUTIONARY SPACES IN GLOBALIZATION: Beijing's Dashanzi Arts District
}

By Laura Tan

eginning in the year 2000, Chinese artists and art groups began
resettlement of factories in an area known as the Dashanzi district, a northeastern segment of Beijing that had gone relatively unnoticed after the Cultural Revolution. Formerly electronic production warehouses, these factories were created during the 1950s for greater socialist (and particularly military) aims (Kiang 5). Although this phenomenon of artists inhabiting factory spaces is rather commonplace in American or European cities, the Chinese government has, in a unique moment of lax governance, "supported" such a district by allowing for its continual existence and growth. Reading the district according to Henri Lefebvre's interpretations of space provides an approach that unifies ideology and the physical site, and reveals the multi-layers necessary and active in the sustenance of the arts district. Lefebvre's seminal work The Production of Space bridged binaries of mental and physical space, drawing attention to its role as a locus for change and revolution. Space is produced, and the ideologies and cultures that are behind the composition of an area are as important as the physical constructions built upon it. Therefore, an area needs to be understood as a "social space" that is dialectically created by a multitude of relations (Lefebvre 68). Neither the history of the arts district, its structures, nor the art that it produces is singularly responsible for creating successful (if short-lived) grassroots urban planning, but rather the dialectic among several competing social facets, as well as our current era of globalization, can be viewed as responsible for this unique moment and physical site of contemporary art. 


\section{Ideology as represented by city planning}

The layout of Beijing, that consists of a methodical series of concentric circles with the center being the Forbidden City, reflects the strict and hierarchal governance prescribed by Imperial China. The circles are appropriately named the First, Second, and Third Ring Roads. These roads were reemphasized by a series of walls that ran alongside them. As a structure, walls not only divide but at the same time classify; they retain and remove the movement of certain peoples. So the method of governance during Imperial China mirrored the hierarchical layout of the city, as the emperor, who was positioned at the center, ruled over those of lesser stature, who ruled over those of even less power. Additionally, the north-south orientation of the city layout reflects an underlying ideology in Imperial China based on Confucius' beliefs, being that man is a product of nature and subservient to it. The physical development of humans demands that they be placed in certain directions, the front being the side that is made visible through sight, and the back that is hidden, or unknown. In the development of the Forbidden City, the front faces south in order for the building to receive the "full rays of the noon sun," while the backside faces "darkness," (Tuan 40) or the unseen. These clear demarcations of structure and power through direction and layout make visible social functions and the central power of the Forbidden City. In what Lefebvre describes as "social space," the hierarchical arrangement of Beijing's walls and roads is already antithetical to socialism because these structures distinguish spaces, and people, from one another. ${ }^{9}$

Although the clear division of space enables power to be directed more pointedly, space can be appropriated for purposes contradictory to hegemonic objectives. If space can reflect and encompass ideologies, then the manipulation of space is also a means

9 According to Wikipedia (2005), a wiki "is a web application that allows users to add content, as on an Internet forum, but also allows anyone to edit the content. The term Wiki also refers to the collaborative software used to create such a website (see Wiki software)." 
of controlling culture. During the Cultural Revolution, city planners understood the physical constrictions on organizing space according to a central-power system. To form a more communal environment, they dismantled the three walls alongside the First, Second, and Third Ring Road to open up the city grounds (Lo 134). Under Mao Zedong's direction, planners also expanded the city away from the Forbidden City, particularly in an east-west direction. For instance, the former Chien Men Train Station located near the city's center was destroyed in favor of a new Beijing rail station in the east, and Tiananmen Square located outside the Imperial Palace was transformed from a T-shape to the open paved area that is recognized today (Lo 134; Rowe and Kuan 95). This general trend towards expansion and decentralization through the transformation of space conforms to socialist ideologies. Common peasants, once relegated to the outskirts, were now central to defining the nation. In 1958, Mao Zedong's "The Great Leap Forward" campaign stated with regards to steel production, "If the Soviets can surpass the U.S. in fifteen years, there is no reason that China cannot surpass the U.S. in fifteen years" (Ma 53). Workers teemed into the countryside to raise the nation's production through the building of new roads, railways, and factory units as China attempted to prove that a classless society of workers were indeed just as, if not more productive, than capitalist economies. The city could now be recognized as a place of production, rather than one of consumption that Mao considered symptomatic of capitalist culture.

In 1957, the Dashanzi factory complex opened ready for workers and socialist allies' efforts (Kiang 33). Positioned northeast of the center of the capital, outside the Fourth Ring Road in a relatively unsettled area, the factories' placements were, in part, ideological. The goal was to spur eastern expansion and de-center sites of production. Soviets backed the plan and both East Germans and Soviets designed the buildings according to Bauhaus principles that recognized the building as a site where the roles of artists and craftsman united and various facets of instruction came together 
(Gropius, 2004). The factories' Bauhaus designs were based on the idea of a communal work environment where the community and the individual reciprocated. So in addition to being a place of work, individuals ate, slept, and had access to basic social services (Kiang 33). Thus, space was divided in a different way to avoid the isolation of any particular stratified groups. This kind of environment allowed all peoples equal access to the same goods and services and more importantly, equal involvement in the creation of the nation. Educational services for the children of workers, as well as a recreational complex including a theater, and a vocational college, were all situated within the district. All these amenities sponsored communal goodwill and spirit in the factories that had, painted on their walls, aphorisms such as "Mao is the red sun in our hearts."

The Cultural Revolution, as a reaction towards western influences of capitalism, needed to legitimize Chinese culture. Reaching back towards tradition to fulfill this aim, however, also evoked the ideology of a central structure of power. To this day, the Forbidden City remains at the heart of Beijing, even with the series of cultural shifts that have taken place, and the general layout of concentric circles still exist, although they have expanded outwards. Reading the space of Beijing in this way also recognizes the dialectic between socialist ideologies that refer to the worker as the locus of agency and the more imperial ideology that places the state and hierarchy as the central controlling agents of power. In other words, the complete appropriation of space for socialist aims was not entirely successful during the Cultural Revolution. Realistically, the ability to raze centuries of an ideology by reconfiguring a space in mere decades is too monolithic a task. Because the amount of a physical, tangible land area does not change, ideologies imbedded within them must deal with new, and differing ideologies. The question now to consider is what kind of a division of space is created in a global economy, and what are the power relations resulting from these new divisions? 


\section{Dashanzi district space relations in globalization}

During the present era of globalization, notions of de-centralized spaces have been challenged. Instead, globalization calls for a "global city," a phrase used by Saskia Sassen to describe a city that has the ability to connect industries, technologies, and commercial centers beyond national boundaries (Sassen 105). Undeveloped areas that lack industry, technology, and strong communications are hence left out of the global equation. For example, as host of the 2008 Olympics, Beijing draws increasing international investment that fuels its efforts to become a major city and stay in the global equation. Dilapidated structures fall daily as donkeys carry away the remnants on a series of carts, and new urban centers, renovated business districts, and high-tech hubs replace the old in the move towards modernization. For instance, Wangfujing, Qianmen, and Xidan, three commercial centers prior to 1949, are again being renovated as shopping districts (Gaubatz 1498). The Haidian Development Zone in the northwest region undergoes further technological advancement, as well as the Shandi Information Industrial Base and the Fengtai Science Park (Huanzhang 190). If this urban expansion were based on socialist ideals, the government would not create specialized districts that support exclusivity and neglect the communal living once possible in the work units of the Cultural Revolution. And although production in terms of exports of goods and services has increased 20 fold, so has private consumption that was once reprimanded by Mao Zedong. In the interests of globalization, the Chinese government with its intensely centralized power, can, with much speed, revamp the urban setting of Beijing to create a city with industry, communication, and technology, and it can do so with little disapproval from the general public. However, if the Dashanzi factory district served as a model of socialism, then why has it too not been destroyed? The factory lies along the road to the airport that serves as a nexus for global travelers, a key position for the possibility of economic productivity. The opportunity to create another shopping district, or high-tech center as the Chinese government suggested for the Dashanzi development 
group, Seven Star (Qixing), is in line with the current ideologies of spatial planning.

Typically, as evidenced by the Cultural Revolution, historical regions are bulldozed to lay the floor plan for the next building or structure that furthers ideological growth. However, the economic drive brought about through global competition concurrently brings cultural exchanges between nations, circulating a maelstrom of democratic ideas in a time when Western nations inculcate China with industries, services, and peoples. Although several grassroots campaigns have been founded by such notable individuals such as Huang Rui and $\mathrm{Xu}$ Yong, these campaigns do not unite entire teams of local individuals who negotiate with city government and planning officials. Chin Chin Yap, a former assistant for an art gallery in Beijing, quoted that these movements, for the most part, have foreign supporters because few local artists have faith that the government will respond to their actions. Their relative inactivity and beliefs are indicative of the government's stronghold over planning and urban development. The local Chinese artist may not be an active civic participant, or even have any influence on this Communist government, but a person of international status such as the President of Switzerland is another separate consideration. Specifically, the President of Switzerland stated on a visit that the district was evidence China was reforming by allowing free expression, which was warmly received by the Chinese government (Mars and Waal 53).

International interest in this region has also spawned the growth of several international galleries, such as the German art gallery White Space and Beijing Tokyo Art Projects. Thus, if the Chinese government demolished the arts district in favor of a high-tech zone, the international consequences and negative feedback received on a global scale would likely be cause enough for second thought. With the expediency and reach of the Internet, any news regarding the status of the district can be easily retrieved, and the foreign interest in the area would add continual pressure on the Chinese government to keep the district intact. Already, a notable artist of the area, 
Huang Rui, claimed that "a reliable source" hinted of plans to keep the district in preparation of the Olympics in 2008 (Simons E10). In a time of globalization, spaces are not as easily divided according to the top-down central planning system of government. The transfer of culture by the movement of individuals, unrestricted by physical demarcative structures, have enabled another set of exchanges and interests. And the question now is not how culture is a part of globalization, but rather how culture cannot be excluded in this international exchange process. Culture and an economy exist in the same physical space; economies exist according to a set of cultural principles.

Although Lefebvre's notion of "social space" may escape the constrictions of materiality that are attributed to an object such as an artwork, the product created within a space is also part of the spatial dialectic. In this case, the concern with the product is not with the art itself, as art may always be dismissed as "art." Its method of communication, whether it is the canvas, screen, sculpture, human body or bodies, for the most part, exists as contained self-expression. Under the label of "art," many readily cast the field as having little significant and direct impact on socio-economic and political issues. Hence the performance art piece at Dashanzi art district that displayed the ripping of the Communist flag is allowed as "art" (Simons E10).

Secondly, art's susceptibility to many interpretations, particularly when the artist feels no comment is necessary, questions the meaning of any artwork. One could interpret the ripping of the Communist flag as the current government's failure to be truly communist, or as the artist's own opinion of communism as a destructive force in society, or both. Furthermore, with the postMao reforms well underway, the backlash on Cultural Revolution ideology has subsided from its initial days during the 1980s and varied explorations of contemporary art have increased. Art functions in Chinese society as "normal" rather than "counter-propaganda" (Hou 52). Within the contemporary art world of modern Beijing, 
art as normalcy may be accurate and true, but in terms of globalization those rules do not apply, especially when Beijing's notoriety as a place of un-free expression surpasses its details. What art has enabled, which is crucial to the district's sustainability, is a product that can be easily disseminated as well as one that draws controversy, because these forms of self-expression are relatively unheard of for an outsider curious about Communist China. Art, because it is contained, photographable, and in many cases easily transported to other countries, satisfies such global requirements.

Additionally, artworks often bridge language barriers; a foreigner will be more willing to interpret an image produced by a Chinese artist rather than a piece of writing. Although the meaning of visual artwork may be deepened by an understanding of the Chinese language, the image is at least somewhat penetrable. If transients had appropriated the factory space as an inexpensive place of residence and produced machine-manufactured goods, then the Chinese government would have likely approved its demolition for a technology center. Producing contemporary art is central to the narrative of sustainability for the district as "social space." This narrative refers to both the space itself and art as product, both of which inform one another about their respective processes and means of consumption (Lefebrve 77). Space, particularly in a city plagued by overcrowding, needs to produce an asset for the global economy in order to be worth sustaining.

As a culturally historic piece amidst a modern landscape, the structure of the factories also play a role in keeping the Dashanzi arts district alive. As one of the few historical constructs left on the relative outskirts of the city, the factories represent a portion of history unintentionally reinvigorated during Beijing's urbanization. Not only is the contemporary art housed there considered unique, but the factory complex reemphasizes this rarity because it is a historical relic associated with the Cultural Revolution. Historic preservation is rare in Beijing, where typically what is historically preserved, i.e. Liulichang Street, becomes redirected around cultural 
tourist consumption (Gaubatz 58). But in the Dashanzi arts district, adaptive reuse of factory spaces employs the angled windows, high ceilings, and large, open windows fill the spaces with light. The architectural quality inherent in the structures themselves makes the contemporary art more unique than if the art were housed in more typical galleries or museums. The district's largest exhibition space, located in Factory 798 (a name that also refers to the name of the district itself), measures 65 meters long, 32 meters in width and 14 in height (Wu 64). Additionally the factories' original purpose of creating a work community has in many cases been reinstalled, since the spatial layout allows for galleries and studios to exist in one area. Artists work, exhibit, sell, and even live there, as well as live with one another. The communal environment now shunned by Beijing city planners in favor of industrialization can occur here because the space is still intact. The double rarity of the art and the factories differentiates the district even further from Beijing and creates a unique moment on the urban landscape for a more subversive setting for contemporary art.

If Lefebvre's theorizations on agency in the appropriation of space are to be further tested, one must question the power relations in globalized spaces, if they suggest the foundations of centrally-governed planning are now shifting. Is the Dashanzi art district representative of a truly revolutionary space? The most obvious danger in reading the space as being a part of globalization fueled through economic gains is the commodification of it. For although the space may escape the politics of centrally-governed planning, it does not escape the greater hegemonic mode of capitalism. If people liken the Dashanzi arts district to New York's SoHo narrative, as the area is often compared to, then capitalist prospects will eventually transform the area into one where few artists can afford to live. What is drastically different however, is the amount of time this will take place. Within a matter of years, the district has already been exposed to increasing rent rates and has witnessed the effects of internationally driven economic growth. Julia Colman 
of London's Chinese Contemporary Gallery notes that in the last several years, artworks that were previously sold for $\$ 100.00$ U.S. dollars or $\$ 50.00$ U.S. dollars are now being sold for $\$ 50,000.00$ or even $\$ 100,000.00$ (Wullschager 35). Colman has recently opened a Beijing gallery at the Dashanzi district, and the factories that once were only inhabited by workers and artists are now frequented by tourists. On the same token, a French restaurant lies in the heart of the district, and Omega recently held a campaign and opened a store there. So although foreign interest and investment were crucial to sustaining the existence of the region thus far, these same forces may be responsible for the loss of what may be called "artistry" in favor of monetary value.

If international attention continues to focus on Chinese contemporary art and the specific historicity of these factories, both of which also imply a greater (more unique) exchange value for product, there is a possibility that the factories as an arts district shall continue to stand. Although the Beijing government may not have controlled the transformation of the region, as a still powerful center of ideology, the government may claim that the Dashanzi arts district represents this post-Mao era of "open reform."10 Although this may be interpreted as a re-inclusion into central planning ideology, the arts district shifted the focus of the institution of control, if only for a moment, in order for the government to reconstitute itself as the place of governance. However, if cultural exchange continues and Western democratic philosophies insidiously cross nations, the implications that globalization then has on typically centrally-governed spaces is a revolutionary one, which people may use as a tool to reappropriate spaces for purposes tangential to government plans.

10 Translation of "gaigekaifang," the phrase used to describe 1980s policy changes. 


\section{Works Cited}

Gaubatz, Piper. "Urban transformation in post-Mao China: impacts on the reform era on China's urban form." Urban Spaces in Contemporary China. Eds. Deborah S. Davis, Richard Kraus, Barry Naughton, and Elizabeth J. Perry. Cambridge: P Syndicate of the U of Cambridge, 1995. 28-60.

---. "China's Urban Transformation: Patterns and Processes of Morphological Change in Beijing, Shanghai and Guangzhou." Urban Studies 8.9 (1999): 1495-1521.

Gropius, Walter. “The Bauhaus Manifesto.” 1919. The Administration of the National Bauhaus at Weimar. Architettura Moderna. 3 Dec. 2004 <http:// www.architetturamoderna.com/pdf/Bauhausmanifesto.pdf>.

Hou, Hanru. "Towards and Un-Unofficial Art: De-ideologicalization in China's Contemporary Art in 1990s.” Third Text 34 (Spring 1996): 37-52.

Ke, Huanzhang. "Beijing 1996-2010: A cross-century development plan." Ekistics (July/Aug.-Nov./Dec. 1997): 189-197.

Kiang, Eliot. "798: Five Glorious Decades." Reflections on Art, Architecture, and Society in China: Beijing 798. Beijing: timezone8 and thinking hands: Beijing, 2004. 32-37.

Kiang, Karon Morano. "Introduction: A New Vocabulary." Reflections on Art, Architecture, and Society in China: Beijing 798. Beijing: timezone8 and thinking hands, 2004. 4-9.

Lefebvre, Henri. The Production of Space. Trans. Donald Nicholson-Smith. Oxford: Blackwell Publishing, 1991.

Lo, C.P. "Shaping Socialist Chinese cities: A model of form and land use." China: Urbanization and National Development. Ed. C.K. Leung and Norton Ginsberg. Chicago: U of Chicago, 1980. 130-155.

Ma, Qingyun. Commentary on Mihai Craciun's “Ideology: Shenzhen.” Project on the City 1. Eds. Chuihua Judy Chung, Jeffrey Inaba, Rem Koolhas, Sze Tsung Leong. Koln: Taschen Gmbh, 2001. 53.

Mars, Neville and Martin de Waal. "Beijing and Beyond." Reflections on Art, Architecture, and Society in China: Beijing 798. Ed. Huang Rui. Beijing: timezone8 and Thinking Hands, 2004. 38-53.

Rowe, Peter G. and Seng Kuan. Architectural Encounters with Essence and Form in Modern China. Cambridge: MIT P, 2002.

Sassen, Saskia. "The Global City: Introducing a Concept and itsHistory."

Mutations. Eds. Francine Fort and Michel Jacques. Barcelona: Actar, 2000. 104-115. 
Simons, Craig. "Amid Ghosts of the Red Guard, The Avant-Garde Now Blooms." The New York Times. Wed., 1 Sept. 2004: E3.

Tuan, Yi-Fu. Space and Place. Minneapolis: U of Minnesota P, 1977.

Wullschager, Jackie. "No more Chinese whispers." Financial Times (London, England). Saturday, 2 Oct. 2004: Arts 35.

Wu, Hung. "Tui-Transfiguration: An Experimental Exhibition at Factory 798." Reflections on Art, Architecture, and Society in China: Beijing 798. Beijing: timezone8 and thinking hands: Beijing, 2004. 58-69.

Yap, Chin Chin. Primary source. Singaporean-born Chin ChinYap worked at an art gallery in Beijing for over a year. She has written articles for Art AsiaPacific and is currently a Georgetown law student. 2004. 